\title{
Variant Case of Sturge-Weber Syndrome
}

Varyant Bir Sturge-Weber Olgusu

\author{
(1) Sinan Eliaçık \\ Hitit University Corum Erol Olcok Training and Research Hospital, Clinic of Neurology, Corum, Turkey
}

Keywords: Sturge-Weber, epilepsy, facial nevus

Anahtar Kelimeler: Sturge-Weber, epilepsi, fasiyal nevüs

\section{Dear Editor,}

A 17-year-old male was admitted to hospital with epileptic seizures. It was learnt that he had seizures since he was aged one year. He had no febrile seizures and his neuromotor development was normal. In his seizures, which lasted less than one minute, his eyes and head deviated to the right and sometimes licking and mouth automatisms were added. It was learnt that his number of seizures sometimes increased and seizures evolved to secondary generalized seizures. It was learnt from his family that he had not used valproic acid regularly for the last one year and he could not receive regular examinations because of socio-economic reasons. There was no feature on his resume. An electroencephalography showed sharp-contoured theta waves and sometimes spike waves in the left temporoparietooccipital area, which became generalized via spreading to homologous areas of the opposite hemisphere. Computed tomography imaging showed cortical atrophy in the left cerebral hemisphere, especially in the parietal lobe with a calcific plaque formation in this area and minimal enlargement of the right lateral ventricle (Figure 1A, 1B). In the follow-up, cranial magnetic resonance imaging (MRI) was performed, which revealed an increase in the number of gyri, signal changes suggestive of polymicrogyria, and cortical dysplasia, calcification, leptomeningeal thickening, and asymmetric enlargement of the right lateral ventricle. Signal intensities of the bilateral hippocampus and corpus callosum were normal (Figures 2A, 2B). Oxcarbazepine was initiated at a dosage of $600 \mathrm{mg} / \mathrm{day}$ and increased up to $1200 \mathrm{mg} /$ day. In the subsequent period, because of adverse events and treatment failure, levetiracetam was added and its dose was increased. With the treatment, the seizure frequency decreased and the patient is still taking treatment.

In the pathophysiology of Sturge-Weber syndrome (SWS), cerebral hypoxia, ischemia, venous occlusion, thrombosis, infarction, atrophy, and vasomotor phenomenon caused by the secondary effects of residual embryonic blood vessels on the surrounding cerebral tissue play an important role (1). Neurologic findings vary due to the location and magnitude of cerebral damage caused by vascular pathologies. Neurologic findings include epilepsy due to cortical dysgenesis, hemiparesis due to unilateral atrophy, mental retardation due to the widespread failure of cerebral blood flow, and migraine-like headache (2). Port wine nevus, one of the characteristic findings of SWS, consists of the malformation of small veins and capillaries under the facial skin. A defect in the development of the primitive cephalic venous system in the first trimester of gestation is thought to cause the abnormality (1). Patients with SWS but without the facial angiomatous lesion, which is the most frequent finding in SWS, have been reported in the literature (3). In another study, rare cerebral imaging findings were discussed in patients with porto wine nevus and patients suspected of having SWS. Typical findings were detected in 32 of 62 patients. In 20 patients, irrelevant MRI findings were seen. In 7 of the remaining 10 patients, pial angiomas were found, pial angioma and cortical calcification were found in 2, in one, the initial MRI was normal and but later showed pial angioma during follow-up (4). In the reported patient,

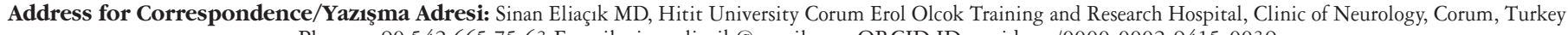
Phone: +90 5426657563 E-mail: sinaneliacik@gmail.com ORCID ID: orcid.org/0000-0002-9415-0039

Received/Geliş Tarihi: 13.03.2017 Accepted/Kabul Tarihi: 01.07.2017

${ }^{\circ}$ Copyright 2018 by Turkish Neurological Society

Turkish Journal of Neurology published by Galenos Publishing House.
} 

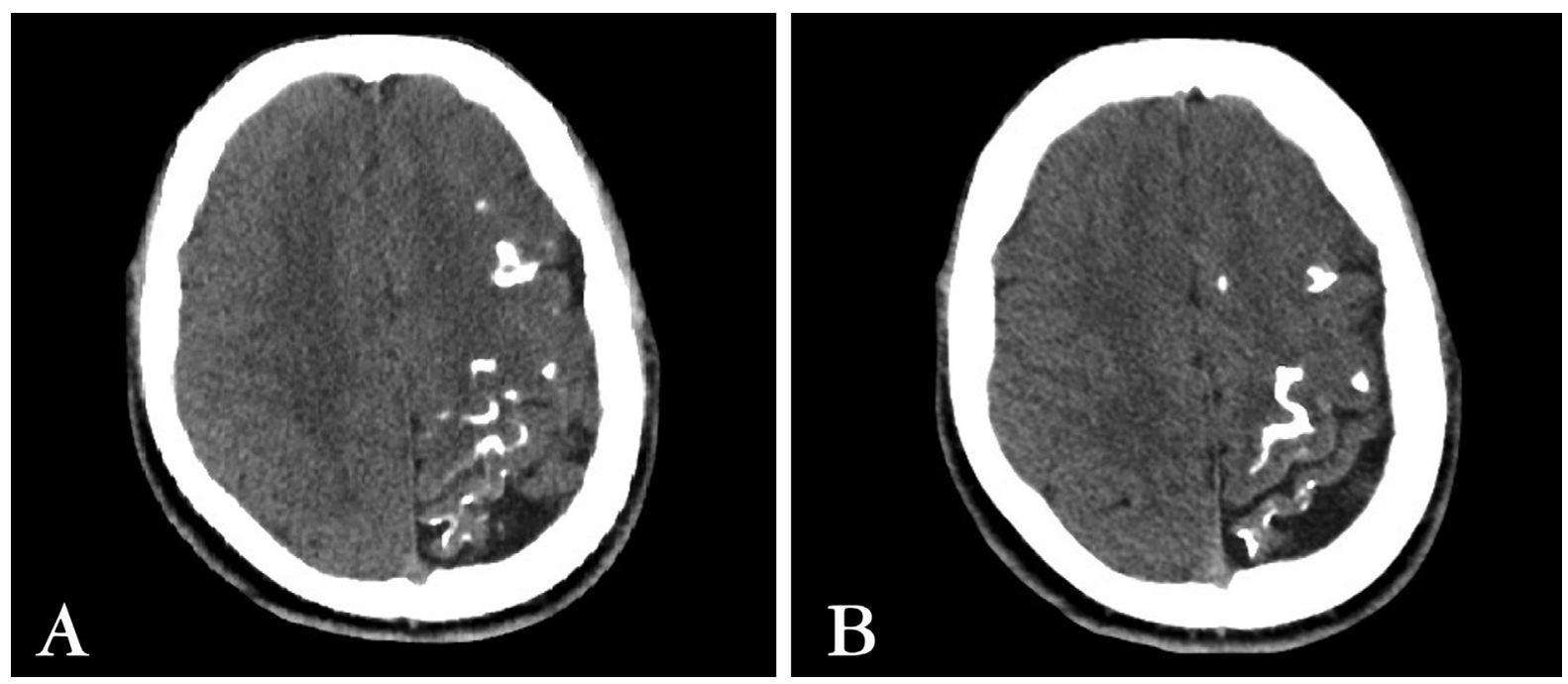

Figure 1. A, B) Computed tomography of the patient with Sturge-Weber syndrome
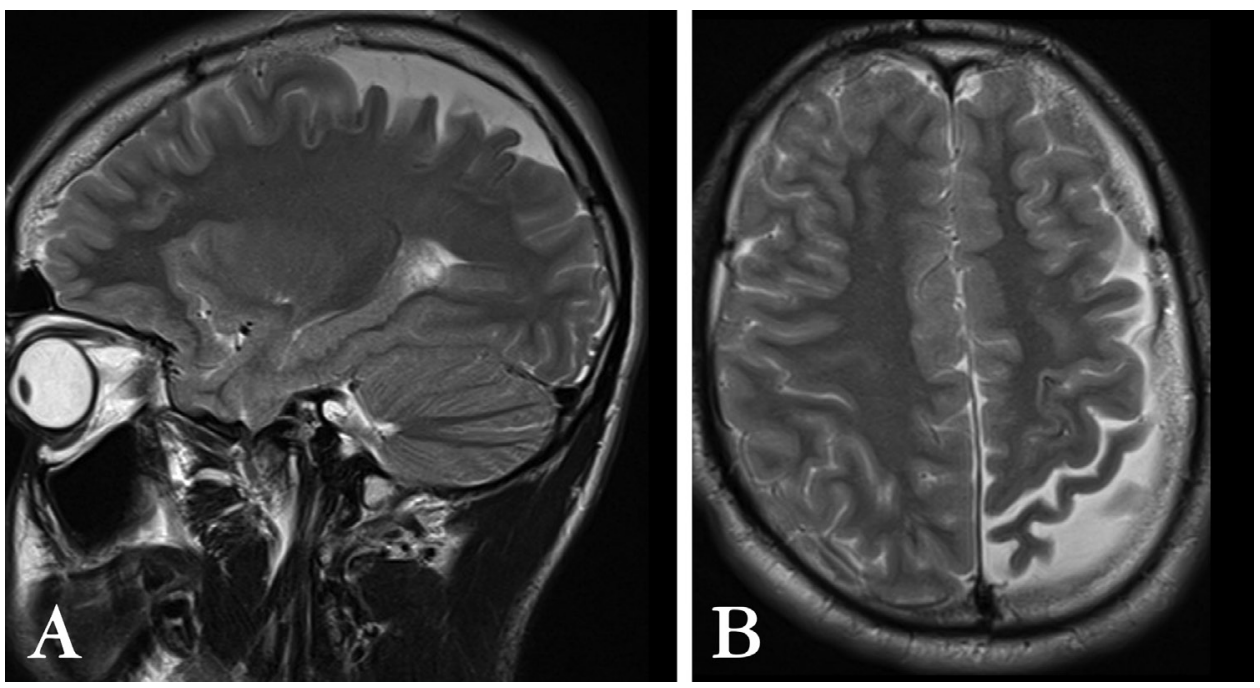

Figure 2. A, B) Sagittal and axial T2 weighted cranial magnetic resonance imaging of the patient with Sturge-Weber syndrome

leptomeningeal thickening, cortical calcification, and atrophy in the left temporoparietooccipital region were found. In the literature, a few patients that could be called 'variant SWS' were reported and classified according to findings of physical and neurologic examinations and imaging findings. The reported patient had similar features to patients with variant SWS. Whether these patients are true variants will be revealed after the pathophysiology of SWS is understood.

Ethics

Informed Consent: Consent form was filled out by all participants.

Peer-review: Internally peer-reviewed.
Financial Disclosure: The author declared that this study has received no financial support.

\section{References}

1. Comi AM. Pathophysiology of Sturge-Weber syndrome. J Child Neurol 2003;18:509-516.

2. Thomas-Sohl KA, Vaslow DF, Maria BL. Sturge-Weber syndrome: a review. Pediatr Neurol 2004;30:303-310.

3. Aydin A, Cakmakçi H, Kovanlikaya A, Dirik E. Sturge-Weber syndrome without facial nevus. Pediatr Neurol 2000;22:400-402.

4. Adams ME, Aylett SE, Squier W, Chong W. A spectrum uf unusual neuroimaging findings in patients with suspected Sturge-Weber syndrome. AJNR Am J Neuroradiol 2009;30:276-281. 